\title{
Family Participation in the Nursing Care of the Hospitalized Patients
}

\author{
Shahla Khosravan ${ }^{1,2}$; Behnam Mazlom ${ }^{3}$; Naiemeh Abdollahzade ${ }^{4}$; Zeinab Jamali ${ }^{4}$; \\ Mohammad Reza Mansoorian ${ }^{1, *}$ \\ ${ }^{1}$ Faculty of Nursing and Midwifery, Gonabad University of Medical Sciences, Gonabad, IR Iran \\ ${ }^{2}$ Social Determents of Health Research Center, Gonabad University of Medical Sciences, Gonabad, IR Iran \\ 3 Department of Biostatics, Gonabad University of Medical Sciences, Gonabad, IR Iran \\ ${ }^{4}$ Department of Biostatics, Gonabad University of Medical Sciences, Gonabad, IR Iran
Student Research Committee, Gonabad university of Medical Sciences, Gonabad, IR Iran \\ *Corresponding Author: Mohammad Reza Mansoorian, Faculty of Nursing and Midwifery, Gonabad University of Medical Sciences, Gonabad, IR Iran. Tel: +98-5337223027-8, Fax: +98- \\ 5337223814, E-mail: mansoorian@gmu.ac.ir
}

Received: June 11, 2013; Revised: July 15, 2013; Accepted: July 27, 2013

\begin{abstract}
Background: Few studies, especially in Iran, have assessed the status of family participation in the care of the hospitalized patients.
Objectives: This study was conducted to assess why family members partake in caregiving of their patients in hospitals, the type of care that family provide, and the outcomes of the participation in the opinions of nurses and family members.

Patients and Methods: In this comparative-descriptive study, data was collected by a two- version researcher-developed questionnaire, from 253 family members of patients by quota sampling method and 83 nurses by census sampling method from wards which had licensed for entering the families. Each questionnaire has three sections: the care needs of the patients which family participated to provide, the reasons to take part, and the outcomes of this collaborative care. The data was analyzed using descriptive statistics and also chi-squared test through SPSS software version 11.5.

Results: The patients received more unskilled and non- professional nursing care from their family members. Most of the nurses and families believed that family participation is both voluntary and compulsory. The shortage of personnel in different categories of nursing and speeding up the patient-related affairs were the most important outcome of the participation, from the nurses' viewpoint was speeding up the patient-related affairs and from the side of the family members, it was the patients' feeling of satisfaction from the presence of one of their relatives beside them.

Conclusions: Co understanding, skillfulness and competence of families and nurses in collaboration with each other were not good enough.Few studies, especially in Iran, have assessed the status of family participation in the care of the hospitalized patients.
\end{abstract}

Keywords: Family Nursing; Hospitalization; Nursing Care

\section{Background}

The main and final goal of nursing is providing the human health. Achieving this goal is possible through scientific care, and also suitable relation of nurses with patient and her/his family (1). It has been emphasized to facilitate the conditions of family' participation and engagement in the care of hospitalized patients (2) due to the history of living the family members with the patient and their knowledge and skills in providing care for the patient (3). Providing this opportunity needs voluntary care of one of the family members and receiving help from personnel which is one of the needs of the family (2). In recent years, health care professionals have accepted appropriate treatment relation and interact between the family and the medical team at the hospital as one of the fundamental components of care (4) and the philosophy of family- centered care has been considered $(5,6)$. While improving the quality of nursing care and more satisfaction of the patients and nurses, as the desired effects of family involvement in the nursing care of patients, have been reported in many studies (7-9), but it should be noted that neglecting the needs of the patients' families and imposing them more responsibilities than their capabilities have adverse effects such as feelings of inadequacy and inability (10). Few studies have assessed status of participation of the patients' family (11) and family and nurses view points in the role of families in caring of their relatives (12). In particular, there is not enough reliable evidence on the status of participation of the families in the care of their patients as one of the key indicators of family- centered care (13) in Iran.

\section{Objectives}

The main goal of this study was to assess the family participations status in the care of hospitalized patient from the nurses' and the families' points of view. In this

Implication for health policy/practice/research/medical education:

Staying family's patients in hospital with their sick to provide care for them sometimes is necessity. But this participation and interaction should not be imposed to the families which can lead to dissatisfaction from the nursing staff due to the feeling of that the families are forced to do these duties, lack of security for the patient families' participation in patients' care needs to be managed and changed.

Copyright (c) 2013, Iranian Red Crescent Medical Journal;; Published by Kowsar Corp. This is an open-access article distributed under the terms of the Creative Commons Attribution License, which permits unrestricted use, distribution, and reproduction in any medium, provided the original work is properly cited. 
regard, three objectives are considered to determine: The reason that a family participates in caring their patient in hospital, the type of the care and the outcomes of the participation.

\section{Patients and Methods}

A comparative- descriptive study was performed in two teaching hospitals, 22 Bahman and 15 Khordad related to Gonabad University of Medical Sciences, in 2011-2012 in Gonabad city, in Iran. The samples of this study were nurses who worked in the wards which had license for entering the patient's family (internal, surgery, emergency, pediatrics, Obstetrics \& Gynecology, and ENT), and families or relatives of patients who had been hospitalized in these wards. Nurses were selected by census sampling; inclusion criteria for nurses was having a bachelor's degree or higher and also having the experience of caring the patients with their family participation (No: 84). The patients' family was selected by quota sampling method to reach to sample size (No: 253), through determining the share of each ward according to auditing calculation of occupied beds in the wards and according to the statistics of the number of patients hospitalized in the above mentioned sections at the first six months of 2011. Inclusion criteria for them was having experience of caring their patients at least one shift in one of the wards in two hospitals and aged at least 18 years who can read and write Persian or answer to the questionnaires orally. The research tools were two researcher-made questionnaires for nurses and patient families. The questions were provided according to a primary interview with the families and the nurses working in the mentioned hospitals, job descriptions of the nursing personnel in Iran and also searching the references. Content and face validity of the questionnaire was further enhanced by submitting it to nursing research and education experts. The reliability of the questionnaires has been assessed by test- retest method and reliability coefficient of 0.7 was obtained for nurses' version and 0.9 for patient families' version. Each questionnaire consisted of demographics and three sections with 70 questions: the patients' care needs for which family participated to provide, the reasons of participation, and the outcomes of collaborative care. The first section of nursing care included 38 questions in five areas: care (11 question), treatment (9 question), supportive - protective (10 question), coordinative (4 question), teaching (4 question); each second and third sections included 16 questions.

This study was approved by the Ethics committee of Gonabad University of Medical Sciences (Code No: 90/8, Date: 15.9.2011). The questionnaires were completed and collected after receiving oral satisfaction with full awareness about the goals of the study No individual identifiable information was included on either the questionnaires or demographics sheet. To consider Patient Privacy, data collections from the families were done at the time of discharge of their patient from hospital. Statistical analysis was carried out using SPSS 11.5 software and the results analyzed using descriptive statistics of frequency, relative frequency, mean and also chi-squared test $\mathrm{P}<0.05$ was considered statistically significant.

\section{Results}

The demographic results showed that from 84 nurses, $14.2 \%$ were male and $85.7 \%$ female with $1-20$ years' experience in nursing with bachelor degree. 16 of them worked in internal ward, 19 in surgery, 23 in emergency, 12 in pediatrics, 11 in Obstetrics \& Gynecology, and 3 in ENT ward. From 253 members of the families, 33.6\% were male and $66.4 \%$ female; more details was shown in Table 1.

Table 1. Demographic Variables Related to Family Members of Patients

\begin{tabular}{|c|c|c|}
\hline Variables & No. & $\%$ \\
\hline \multicolumn{3}{|l|}{ Gender } \\
\hline Female & 168 & 66.4 \\
\hline Male & 85 & 33.6 \\
\hline Total & 253 & 100 \\
\hline \multicolumn{3}{|l|}{ Age (Year) } \\
\hline 20-29 & 137 & 54.1 \\
\hline $30-39$ & 92 & 36.4 \\
\hline 40 and more & 24 & 9.5 \\
\hline Total & 253 & 100 \\
\hline \multicolumn{3}{|l|}{ Education } \\
\hline Illiterate & 69 & 27.3 \\
\hline Diploma and less & 154 & 60.8 \\
\hline Higher Education & 30 & 11.9 \\
\hline Total & 253 & 100 \\
\hline \multicolumn{3}{|l|}{ Residence } \\
\hline Rural & 143 & 56.5 \\
\hline Urban & 110 & 43.5 \\
\hline Total & 253 & 100 \\
\hline \multicolumn{3}{|l|}{ Ward } \\
\hline Surgery & 38 & 15 \\
\hline Internal & 64 & 25.2 \\
\hline Urgency & 65 & 25.7 \\
\hline $\begin{array}{l}\text { Obstetrics and Gyne- } \\
\text { cology }\end{array}$ & 35 & 13.8 \\
\hline ENT & 23 & 9 \\
\hline Pediatric & 28 & 11.3 \\
\hline Total & 253 & 100 \\
\hline \multicolumn{3}{|l|}{ Hospital } \\
\hline 22 Bahman & 215 & 84.9 \\
\hline 15 Khordad & 38 & 15.1 \\
\hline Total & 253 & 100 \\
\hline
\end{tabular}


Table 2. Nurses and Families Perspective About the Type of Participated Care Affairs

\begin{tabular}{lllll}
\hline Care Affairs & \multicolumn{2}{c}{ Patient's Family Assigned } & \multicolumn{2}{c}{ Nurse Assigned } \\
\cline { 2 - 5 } & No. & $\%$ & No. & \% \\
\hline Taking the samples to laboratory & 155 & 61.3 & 45 & 71.6 \\
\hline Emptying the urine bag & 91 & 36 & 70 & 92.9 \\
\hline Arising the patient and feeding patient & 205 & 81 & 42 & 50 \\
\hline Changing the cloth & 171 & 67.6 & 3 & 3.6 \\
Changing the bed sheet & 41 & 16.2 & 22 & 26.2 \\
\hline Active and inactive exercises & 87 & 34.4 & 0 & 0 \\
\hline Placing the temperature & 51 & 20.4 & 69 & 82.2 \\
\hline Placing and removing the basin for defecation & 120 & 47.4 & 47 & 56 \\
\hline Changing children diaper and cleaning them & 53 & 20.9 & 10 & 11.9 \\
\hline Patient's respiratory physiotherapy & 35 & 13.8 & & 78 \\
\hline
\end{tabular}

\begin{tabular}{|c|c|c|c|c|c|c|c|c|}
\hline \multirow[t]{2}{*}{ Groups } & \multicolumn{2}{|c|}{$\begin{array}{l}\text { Agreed Nurses, } \\
\qquad \mathbf{n}=\mathbf{8 4}\end{array}$} & \multicolumn{2}{|c|}{$\begin{array}{l}\text { Agreed Family, } \\
\quad \mathbf{n}=\mathbf{2 5 3}\end{array}$} & \multirow[t]{2}{*}{$\begin{array}{l}\mathbf{P} \\
\text { value }\end{array}$} & \multirow[t]{2}{*}{$\begin{array}{l}\text { Odds } \\
\text { Ratio }\end{array}$} & \multicolumn{2}{|c|}{$\begin{array}{c}\text { Confidence } \\
\text { Interval }\end{array}$} \\
\hline & No. & $\%$ & No. & $\%$ & & & Low & Upper \\
\hline Not having enough time & 43 & 51 & 53 & 20 & 0.999 & 0.253 & 0.150 & 0.427 \\
\hline Speeding up the patient-related affairs & 44 & 52 & 147 & 58 & 0.359 & 1.261 & 0.768 & 2.070 \\
\hline Ward being busy & 58 & 69 & 92 & 39.4 & 0.999 & 0.256 & 0.151 & 0.435 \\
\hline $\begin{array}{l}\text { Shortage of personnel in different categories of } \\
\text { nursing }\end{array}$ & 58 & 72 & 77 & 30 & 0.999 & 0.165 & 0.095 & 0.286 \\
\hline $\begin{array}{l}\text { Many specialized tasks causes assigning non-spe- } \\
\text { cialized tasks }\end{array}$ & 30 & 35.7 & 28 & 11.1 & 0.999 & 0.224 & 0.124 & 0.406 \\
\hline Nurse fatigue & 16 & 19 & 43 & 17 & 0.667 & 0.870 & 0.461 & 1.643 \\
\hline $\begin{array}{l}\text { Too much attention of the nurses to the account- } \\
\text { ing tasks such as writing files }\end{array}$ & 22 & 26.2 & 64 & 25.3 & 0.871 & 0.954 & 0.543 & 1.676 \\
\hline Neglect and carelessness of the personnel & 7 & 8.3 & 46 & 18.2 & 0.032 & 2.444 & 1.058 & 5.646 \\
\hline $\begin{array}{l}\text { Routinely performing the patient's tasks by the } \\
\text { family }\end{array}$ & 28 & $3 / 33$ & 50 & $8 / 19$ & 0.011 & 0.493 & 0.284 & 0.583 \\
\hline Not informed about duties & 3 & 3.6 & 51 & 20 & 0.999 & 6.817 & 2.068 & 22.465 \\
\hline Working in several consecutive shifts & 17 & 20.2 & 47 & 18.6 & 0.737 & 0.899 & 0.484 & 1.671 \\
\hline $\begin{array}{l}\text { Unsuitable wage rather than high volume of the } \\
\text { tasks }\end{array}$ & 10 & 11.9 & 23 & 9.1 & 0.452 & 0.740 & 0.337 & 1.626 \\
\hline $\begin{array}{l}\text { keeping the patient's privacy and religious prob- } \\
\text { lems }\end{array}$ & 26 & 31 & 79 & 31.2 & 0.963 & 1.013 & 0.594 & 1.727 \\
\hline $\begin{array}{l}\text { Not coordinating of the patient with hospital } \\
\text { personnel }\end{array}$ & 10 & 11.9 & 50 & 19.8 & 0.103 & 1.823 & 0.879 & 3.779 \\
\hline $\begin{array}{l}\text { For more participation as the nearest person } \\
\text { beside patient }\end{array}$ & 34 & 40.5 & 128 & 50.6 & 0.108 & 1.506 & 0.913 & 2.484 \\
\hline Family's high level of education & 6 & 7.1 & 21 & 8.3 & 0.735 & 1.177 & 0.485 & 3.021 \\
\hline
\end{tabular}


Khosravan S et al.

\begin{tabular}{|c|c|c|c|c|c|c|c|c|}
\hline \multirow[t]{2}{*}{ Outcomes } & \multicolumn{2}{|c|}{$\begin{array}{l}\text { Agreed Nurses, } \\
\quad \mathbf{n}=\mathbf{8 4}\end{array}$} & \multicolumn{2}{|c|}{$\begin{array}{l}\text { Agreed Family, } \\
\quad \mathrm{n}=253\end{array}$} & \multirow[t]{2}{*}{ Pvalue } & \multirow[t]{2}{*}{$\begin{array}{l}\text { Odds } \\
\text { Ratio }\end{array}$} & \multicolumn{2}{|c|}{$\begin{array}{l}\text { Confidence } \\
\text { Interval }\end{array}$} \\
\hline & No. & $\%$ & No. & $\%$ & & & Low & Upper \\
\hline Not correctly performing the assigned duty & 34 & 26.9 & 68 & 26.9 & 0.019 & 0.541 & 0.322 & 0.906 \\
\hline Duplication & 26 & 22.2 & 56 & 22.2 & 0.107 & 0.637 & 0.368 & 1.104 \\
\hline Decreasing the nurse value & 16 & 13.8 & 35 & 13.8 & 0.248 & 0.682 & 0.365 & 2.094 \\
\hline $\begin{array}{l}\text { Family no satisfaction from the patient hospital- } \\
\text { ization in hospital }\end{array}$ & 15 & 19.4 & 49 & 19.4 & 0.760 & 1.105 & 0.583 & 2.094 \\
\hline Damage to patient's health & 11 & 29.6 & 75 & 29.6 & 0.003 & 2.796 & 1.404 & 5.569 \\
\hline Request for discharge before the determined time & 8 & 19 & 48 & 19 & 0.044 & 2.224 & 1.006 & 4.918 \\
\hline Speeding up the patient-related affairs & 53 & 43.9 & 111 & 43.9 & 0.002 & 0.457 & 0.275 & 0.760 \\
\hline Respect for patient privacy and religious issues & 31 & 36.4 & 92 & 36.4 & 0.929 & 0.977 & 0.580 & 1.630 \\
\hline $\begin{array}{l}\text { The patient's feeling of satisfaction from the pres- } \\
\text { ence of family }\end{array}$ & 47 & 69.6 & 176 & 69.6 & 0.090 & 1.554 & 0.932 & 2.592 \\
\hline $\begin{array}{l}\text { Participation and interaction between nurse and } \\
\text { patient's family }\end{array}$ & 43 & 42.3 & 97 & 42.3 & 0.155 & 0.699 & 0.426 & 1.147 \\
\hline The feeling of being useful as the patient's family & 24 & 49.4 & 125 & 49.4 & 0.001 & 2.441 & 2.432 & 4.163 \\
\hline Increasing the patient's costs & 1 & 1.2 & 33 & 13 & 0.002 & 12.450 & 1.676 & 92.491 \\
\hline Physical and verbal confrontation with nurse & 9 & 10.7 & 28 & 11.1 & 0.929 & 1.037 & 0.468 & 2.297 \\
\hline Intervention in treatment & 19 & 22.6 & 39 & 15.4 & 0.130 & 0.623 & 0.337 & 1.153 \\
\hline Causing problem for patient's health & 7 & 8.3 & 65 & 25.7 & 0.001 & 3.803 & 1.669 & 8.666 \\
\hline Increasing the social respect for nurse personnel & 7 & 8.3 & 68 & 26.9 & 0.999 & 4.043 & 1.777 & 9.200 \\
\hline
\end{tabular}

The familys' participation for performing patients' care affairs was more in night shifts comparing to the morning shifts. Only $3.6 \%$ of nurses and $7.6 \%$ of the families believed that performing the affairs by the families is compulsory, while $44 \%$ of the nurses and $45.5 \%$ of the families believed that performing the affairs by the families is completely voluntary. Other nurses and family believed that performing the affairs by the family is both voluntary and compulsory. In relation to the first objective, determining the type of participated nursing duties, the results showed that according to the viewpoint of the families, they participated in performing care (37.62), coordinative (30.04), teaching affairs (28.06), supportive - protective (26.40), and treatment (18.93), while in the viewpoint of the nurses, the families' participated duties were care (43.06), supportive - protective (30.06), treatment (20.04), teaching (14.26) and coordinative affairs (12.20), respectively. Therefore, from the viewpoints of the nurses and families, the care affair was the most common family's participated duties and among these affairs, moving and feeding the patient (92.7) were as in priority; others were shown in Table 2 . Results related to the causes of participation of families in patients' care as the second objective and determining the outcomes of participation from the viewpoint of the nurses and the families are shown in Tables 3 and 4 respectively.

\section{Discussion}

The results of this study showed that family often volun- tary participated in the caring for relatives, especially in the primary care (Table 1 ). The results of other researches also suggested that family cares perceived themselves to have a greater role in caring for relatives were mostly satisfied with their role (11). According to Aiken et al. (14), and also based on the job description of nurses (15), most of the assigned primary care affairs are the duties of assisted nurses. Based on the results of this study, among other tasks, the specialized treatment affairs such as injections and dressing which are the main tasks of educated nurses in Iran are the least affairs assigned to the patient's family. The results of other study in other countries also showed that primary care affairs were performed by families and specialized affairs were carried out by nurses (11 ,12). Due to this situation patients frequently complained about the lack of care needs by nurses and used the support of one of their family members for doing these care affairs (11).

The results of this study also showed that doing the affairs for the patient were in the rate of mainly involuntary to voluntary condition. While, other results showed that despite most of the families of hospitalized children (mothers) wanted the desired care by the nurses for their child, but this was not performed and finally doing was assigned to the mothers (16). The other study suggests that families' tendency to participate in patient care is very important morally and the families don't have any responsibility for the care of patients legally; therefore, they should not be asked to do more than what they want 
or they can do (17); also desire and tendency of the family for involvement in patient's care does not mean that they have enough ability to provide adequate care or willingness to perform the imposed responsibilities, rather they want to do the care affairs voluntarily with help of the personnel $(18,19)$. In this study, both nurses and families believed that the most common cause of assigning some of the cares to the families is shortage of personnel in different categories of nursing and the families accept these care affairs either mandatory or optional to perform their patient's care affairs quickly. The result of other study showed that this shortage includes different categories of professional nurse and assisted nurse and the shortage of nurse group leads to using of the families for performing nursing care (20-22). Also the results showed that the families and nurses reported that consecutive shifts of the personnel are the cause of assigning some of the nursing care to the families. Other study also demonstrated mandatory and voluntary overtime (more than 40 hours in week) could negatively impact nurse and patient safety, and significantly related with adverse events and errors, including needlestick injuries, workrelated injuries, patient falls with injury, nosocomial infections, and medication errors (23).

Our study showed that the most common cause of assigning some of the cares being lack of time related to focusing the nurse on tasks such as documentation. Other study also suggested that, nurses are faced with multiple tasks and much of the theirs' time has been spent on the non-specialized tasks; they are engaged in tasks that are more similar to secretary duties and therefore, the main task of professional nurse and meaningful relationships with patients and their families has not been made due to the shortage of time (24). Maintaining the privacy of patient and providing care by the nurses of the same gender, related to Islamic religious culture in Iran, is another factor that suggested the necessity of participation of family to provide care when there is no such nurse. The theme of noticing to culture (25) Islamic values in providing the nursing care based on professional ethics have suggested in other studies $(26,27)$.

The results of this study showed that participation in providing care has positive consequences such as accelerating the performance of the affairs, and also the negative consequences such as not correctly performing of assigning task, damage to patient's health and their relatives. According to other study, although providing care by the family can make feeling of security and comfort for the patient, but in some cases, due to lack of sufficient information of the family, it leads to the patient's worry some and a sense of insecurity (28) and also families are faced with a constant tension due to forced and imposed care of their patients $(16,18,19)$. Increasing the patient's costs and request for discharge before the determined time was another consequences of this research from viewpoint of families. According to other researchers increasing hospital costs associated with the presence of family provides the background for dissatisfaction and complaint $(18,29)$, and in some cases, leads to verbal and physical violence against nurses by patients and their family (30-33)

In this study, causing health problems for the families was one of the outcomes of assigning the affairs. According to other studies neglecting the needs of the patients' families due to poor physical environment and lack of hospital facilities to meet the minimum basic needs of human health (34) have negative effect on the family's health and imposing over responsibility to them have adverse effects such as feelings of inadequacy, inability (9), psychological burden (29), anxiety, depression (35), tiredness and feeling of being alone in their patient care responsibilities (4). Although this study tried to present the status of participation of the families in the care of their patients, but the data was collected by a self- report questionnaire with a convenience sampling strategy. We recommended data gathering method improve in following studies.

Interaction and relation of the families with the hospital treatment team is one of the essential components of care; but this need was not properly met; effective presence of the nurse can balance the role of the family beside the patient. In this regard, training the personnel for better and more understanding of the families and involving them in the care based on their abilities according to the philosophy of family- centered care has been suggested.

\section{Acknowledgements}

The authors would like to thank this committee and also, thank from the patients and nurses participated in this study.

\section{Authors' Contributions}

All authors have participated in doing research and writing the article.

\section{Financial Disclosure}

There is no financial disclosure.

\section{Funding Support}

The research was supported by Gonabad University of Medical Sciences, Gonabad, IR Iran.

\section{References}

1. Molazem Z, Ahmadi F, Mohammadi E, Bolandparvaz S. Improvement in the nursing care quality in general surgery wards: Iranian nurses' perceptions. Scand J Caring Sci. 2011;25(2):350-6.

2. Astedt-Kurki P, Paunonen M, Lehti K. Family members' experiences of their role in a hospital: a pilot study. $J$ Adv Nurs. 1997;25(5):908-14.

3. Laitinen-Junkkari P, Merilainen P, Sinkkonen S. Informal caregivers' participation in elderly-patient care: an interrupted timeseries study. Int J Nurs Pract. 2001;7(3):199-213.

4. James SR, Ashwill JW. Nursing Care of Children: Principles and Prac- 
tice. 3th edUSA: Saunders/Elsevier; 2007.

5. Griffin T. Family-centered care in the NICU. J Perinat Neonatal Nurs. 2006;20(1):98-102.

6. Coyne I, O'Neill C, Murphy M, Costello T, O'Shea R. What does family-centred care mean to nurses and how do they think it could be enhanced in practice. J Adv Nurs. 2011;67(12):2561-73.

7. Black P, Boore JR, Parahoo K. The effect of nurse-facilitated family participation in the psychological care of the critically ill patient. J Adv Nurs. 2011;67(5):1091-101.

8. Soleimani M, Rafii F, Seyedfatemi N. Participation of patients with chronic illness in nursing care: An Iranian perspective. Nurs Health Sci. 2010;12(3):345-51.

9. Paliadelis P, Cruickshank M, Wainohu D, Winskill R, Stevens H. Implementing family-centred care: an exploration of the beliefs and practices of paediatric nurses. Aust J Adv Nurs. 2005;23(1):316.

10. Sharp T. Relatives' involvement in caring for the elderly mentally ill following long-term hospitalization. J Adv Nurs. 1990;15(1):6773.

11. Mukoro UfuomaogheneJ. The Level of Family Involvement in the Nursing Care of Hospitalized Geriatric Patients in Two Teaching Hospitals in South Western Nigeria. Stud Home Com Sci. 2011;5(3):169-76.

12. Ryan AA, Scullion HF. Family and staff perceptions of the role of families in nursing homes. J Adv Nurs. 2000;32(3):626-34.

13. McSherry R, Pearce P, Grimwood K, McSherry W. The pivotal role of nurse managers, leaders and educators in enabling excellence in nursing care. J Nurs Manag. 2012;20(1):7-19.

14. Aiken LH, Clarke SP, Sloane DM, International Hospital Outcomes Research Consortium. Hospital staffing, organization, and quality of care: cross-national findings. Int J Qual Health Care. 2002;14(1):5-13.

15. Nursing General and Professional Duties. Nursing administration, administrative management and evolution development.: center of Ministry of Health and medical education; 2009.

16. Aein F, Alhani F, Mohammadi E, Kazemnejad A. Parental participation and mismanagement: a qualitative study of child care in Iran. Nurs Health Sci. 2009;11(3):221-7.

17. Lyytinen H, Liippo T, Routasalo P, Arve S. Older patients' first 72 hours in hospital. Int J Nurs Pract. 2002;8(4):191-7.

18. Shields L, Pratt J, Hunter J. Family centred care: a review of qualitative studies. J Clin Nurs. 2006;15(10):1317-23.

19. Mitchell ML, Chaboyer W. Family Centred Care--a way to connect patients, families and nurses in critical care: a qualitative study using telephone interviews. Intensive Crit Care Nurs. 2010;26(3):154-60.

20. Nayeri ND, Nazari AA, Salsali M, Ahmadi F. Iranian staff nurses' views of their productivity and human resource factors improving and impeding it: a qualitative study. Hum Resour Health. 2005;3:9.

21. Zarea K, Negarandeh R, Dehghan-Nayeri N, Rezaei-Adaryani M Nursing staff shortages and job satisfaction in Iran: issues and challenges. Nurs Health Sci. 2009;11(3):326-31.

22. Yam BM, Rossiter JC. Caring in nursing: perceptions of Hong Kong nurses. J Clin Nurs. 2000;9(2):293-302.

23. Olds DM, Clarke SP. The effect of work hours on adverse events and errors in health care. J Safety Res. 2010;41(2):153-62.

24. Jouybari L, Osquiee F, Ahmadi F. Patients' comfort: a model presentation. J Iran Univ Med Sci. 2005;45(12):59-68.

25. Borhani F, Alhani F, Mohammadi E, Abbaszadeh A. Professional Ethical Competence in nursing: the role of nursing instructors. $J$ Med Ethics Hist Med. 2010;3:3.

26. Anoosheh M, Zarkhah S, Faghihzadeh S, Vaismoradi M. Nursepatient communication barriers in Iranian nursing. Int Nurs Rev. 2009;56(2):243-9.

27. Fakhr-Movahedi A, Salsali M, Negharandeh R, Rahnavard Z. A qualitative content analysis of nurse-patient communication in Iranian nursing. Int Nurs Rev. 2011;58(2):171-80.

28. Taylor SE. Health psychology.Singapore: MCGraw Hill Higher Education; 2006.

29. Shields L, Pratt J, Hunter J. Family centred care: a review of qualitative studies. J Clin Nurs. 2006;15(10):1317-23.

30. Tzeng HM, Yin CY. Family involvement in inpatient care in Taiwan. Clin Nurs Res. 2008;17(4):297-311.

31. Kamchuchat C, Chongsuvivatwong V, Oncheunjit S, Yip TW, Sangthong R. Workplace violence directed at nursing staff at a general hospital in southern Thailand. J Occup Health. 2008;50(2):201-7.

32. Kennedy MP. Violence in emergency departments: underreported, unconstrained, and unconscionable. Med J Aust. 2005;183(7):362-5.

33. Kingma M. Workplace violence in the health sector: a problem of epidemic proportion. Int Nurs Rev. 2001;48(3):129-30.

34. Hegney D, Plank A, Parker V. Workplace violence in nursing in Queensland, Australia: a self-reported study. Int J Nurs Pract. 2003;9(4):261-8.

35. Muntlin A, Gunningberg L, Carlsson M. Patients' perceptions of quality of care at an emergency department and identification of areas for quality improvement. J Clin Nurs. 2006;15(8):1045-56.

36. Davidson JE, Powers K, Hedayat KM, Tieszen M, Kon AA, Shepard $\mathrm{E}$, et al. Clinical practice guidelines for support of the family in the patient-centered intensive care unit: American College of Critical Care Medicine Task Force 2004-2005. Crit Care Med. 2007;35(2):605-22. 